\title{
Doubt fuzzy ideals of BF-algebra
}

\author{
S. R. Barbhuiya \\ Department of Mathematics, SrikishanSarda College,Hailakandi,Assam,India
}

\begin{abstract}
The aim of this paper is to introduce the notion of Doubt fuzzy ideals of BF -algebra and to investigate some of their basic properties.

Keywords:BF-algebra, Subalgebra, Doubt fuzzy BF -Subalgebra, Doubt fuzzy ideals of BF-algebra

\section{Introduction}

In 1966, Imai and Iseki[1] introduced two classes of abstract algebras viz. BCK-algebras and BCIalgebras. The class of BCK-algebras is a proper subclass of the class of BCI-algebras. J. Neggers and H. S. Kim [2] introduced the notion of B-algebra which is a generalisation of BCK-algebras. Walendziak [3] introduced the notion of BF-algebras, which is a generalization B-algebras andsubsequently fuzzy BF-subalgebra were introduced by Saeid and Rezvani [4, 5] in 2009. Y. B. Jun [6] introduced the notion of Doubt fuzzy ideals in $\mathrm{BCK} / \mathrm{BCI}$-algebras. R. Biswas [7] introduced the concept of anti fuzzy subgroup. Modifying their idea, in this paper we apply the idea of BF-algebras to introduce the notion of Doubt fuzzy ideal of BF-algebras and establish some of their basic properties.
\end{abstract}

\section{Preliminaries}

In this section, we recallsome basic concepts which would beused in the sequel.

Definition 2.1. A BF-algebra is a non-empty set $\mathrm{X}$ with a constant 0 and a binary operation * satisfying the following axioms:

(i) $\quad \mathrm{x} * \mathrm{x}=0$

(ii) $\quad \mathrm{x} * 0=\mathrm{x}$

(iii) $\quad 0 *(\mathrm{x} * \mathrm{y})=\mathrm{y} * \mathrm{x}$ for all $\mathrm{x}, \mathrm{y} \in \mathrm{X}$

For brevity we also call $\mathrm{X}$ a BF-algebra.A binary relation ' $\leq$ ' on $\mathrm{X}$ can be defined by $\mathrm{x} \leq \mathrm{y}$ if and only if $\mathrm{x} * \mathrm{y}=0$.

Example 2.2. Let $\mathrm{R}$ be the set of real numbers and $\mathrm{X}=(\mathrm{R}, *, 0)$ be the algebra with the operation * defined by

$\mathrm{x} * \mathrm{y}=\left\{\begin{array}{l}x \text { if } y=0 \\ y \text { if } x=0 \\ 0 \text { otherwise }\end{array}\right.$

then $\mathrm{X}$ is a BF-algebra.

Definition 2.3. A non-empty subset $S$ of a BF-algebra $X$ is called a subalgebra of $X$ if $x * y \in S$, for all $x, y \in S$.

Definition 2.4. A nonempty subset I of a BF-algebra $\mathrm{X}$ is said to be an ideal of $\mathrm{X}$ if

(i) $\quad 0 \in \mathrm{I}$

(ii) $\quad x * y \in I$ and $y \in I \Rightarrow x \in I$

Definition 2.5. A fuzzy subset $\mu$ of $X$ is called a fuzzy subalgebra of a BF-algebra $X$ if $\mu(\mathrm{x} * \mathrm{y}) \geq \min \{\mu(\mathrm{x}), \mu(\mathrm{y})\}$ for all $\mathrm{x}, \mathrm{y} \in \mathrm{X}$.

Definition 2.6. A fuzzy set $\mu$ of a BF-algebra $\mathrm{X}$ is called a fuzzy ideal of $\mathrm{X}$ if it satisfies the following conditions. 
(i) $\quad \mu(0) \geq \mu(x)$

(ii) $\quad \mu(\mathrm{x}) \geq \min \{\mu(\mathrm{x} * \mathrm{y}), \mu(\mathrm{y})\}$

Definition 2.7. A fuzzy set $\mu$ of a BF-algebra $X$ is called a doubt fuzzy subalgebra of $X$ if $\mu(x * y) \leq \max \{\mu(x), \mu(y)\} \forall x, y \in X$.

\section{Doubt fuzzy ideal}

Definition 3.1. A fuzzy set $\mu$ of BF-algebra $X$ is called a doubt fuzzy (DF) ideal of $X$ if

(i) $\quad \mu(0) \leq \mu(x)$

(ii) $\mu(\mathrm{x}) \leq \max \{\mu(\mathrm{x} * \mathrm{y}), \mu(\mathrm{y})\}$

Example 3.2. Let $X=\{0,1,2\}$ with the following Cayley table.

\begin{tabular}{|l|l|l|l|}
\hline$*$ & 0 & 1 & 2 \\
\hline 0 & 0 & 1 & 2 \\
\hline 1 & 1 & 0 & 0 \\
\hline 2 & 2 & 0 & 0 \\
\hline
\end{tabular}

Then $(X, *, 0)$ is a BF-algebra.Define a fuzzy set $\mu: X \rightarrow\left[\begin{array}{ll}0 & 1\end{array}\right]$ by $\mu(0)=0.1, \mu(1)=\mu(2)=0.4$ then $\mu$ is a doubt fuzzy ideal of $\mathrm{X}$.

Example 3.3. In above algebra if we take $\mu(0)=0.2, \mu(1)=0.3, \mu(2)=0.6$ then $\mu$ is a doubt fuzzy subalgebra of $\mathrm{X}$.

Definition 3.4. Let $\mu$ be a fuzzy set of a BF-algebra Xfor $t \in[01]$, then the sets $\mu_{\mathrm{t}}=\{\mathrm{x} \in \mathrm{X} \mid \mu(\mathrm{x}) \geq \mathrm{t}\}$

$\mu^{t}=\{x \in X \mid \mu(x) \leq t\}$

could be empty sets. The set $\mu_{t}=\varphi$ (respt. $\mu^{t} \neq \varphi$ )is called the $t$ (respt t-doubt) confidenceset of $\mu$.

Theorem 3.5. $\mu$ is a fuzzy subalgebra of BF-algebra $\mathrm{X}$ iff $\mu$ isempty or subalgebra of $\mathrm{X}$ for all $\mathrm{t} \in\left[\begin{array}{ll}0 & 1\end{array}\right]$.

Proof.Suppose $\mu$ is fuzzy subalgebra of $X$

Therefore $\mu\left(x^{*} y\right) \geq \min \{\mu(x), \mu(y)\}$

To prove $\mu_{\mathrm{t}}$ is a subalgebra of $\mathrm{X}$

Let $\quad \mathrm{x}, \mathrm{y} \in \mu_{\mathrm{t}} \Rightarrow \mu(\mathrm{x}), \mu(\mathrm{y}) \geq \mathrm{t}$

Now $(1) \Rightarrow \mu\left(x^{*} y\right) \geq \min \{t, t\}=t$

$\Rightarrow \mathrm{x}^{*} \mathrm{y} \quad \in \mu_{\mathrm{t}}$

Conversely

Let $\mu_{t}$ is a subalgebra of $X$.

To prove $\mu$ is a fuzzy subalgebra of $X$. Let $x, y \in X$ such that $\mu(x)=t$ and $\mu(y)=s$ where $t \leq s$

Then $\mathrm{x}, \mathrm{y} \in \mu_{\mathrm{t}}$ and so $\left(\mathrm{x}^{*} \mathrm{y}\right) \in \mu_{\mathrm{t}}\left[\mu_{\mathrm{t}}\right.$ is a subalgebra of $\left.\mathrm{X}\right]$

$\Rightarrow \mu\left(\mathrm{x}^{*} \mathrm{y}\right) \geq \mathrm{t}=\min \{\mu(\mathrm{x}), \mu(\mathrm{y})\}$

Hence $\mu$ is a fuzzy subalgebra of $X$.

Theorem 3.6. $\mu$ is a fuzzy ideal of BF-algebra X iff $\mu_{\mathrm{t}}$ is idealof Xt $\in\left[\begin{array}{ll}0 & 1\end{array}\right]$.

Proof.Assume $\mu$ is a fuzzy ideal of $X$. Here $\mu_{t}=\{x \in X \mid \mu(x) \geq t\}$

Clearly $0 \in \mu_{\mathrm{t}}$ since $\mu(0) \geq \mathrm{t}$

Let $\mathrm{x} * \mathrm{y}, \mathrm{y} \in \mu_{\mathrm{t}}$ i.e $\mu\left(\mathrm{x}^{*} \mathrm{y}\right) \geq \mathrm{t}, \mu(\mathrm{y}) \geq \mathrm{t}$

$\mu(\mathrm{x}) \geq \min \{\mu(\mathrm{x} * \mathrm{y}), \mu(\mathrm{y})\} \geq \min \{\mathrm{t}, \mathrm{t}\}$

$\Rightarrow \mathrm{x} \in \mu_{\mathrm{t}}$

Therefore $\mathrm{x}^{*} \mathrm{y}, \mathrm{y} \quad \in \mu_{\mathrm{t}} \Rightarrow \mathrm{x} \in \mu_{\mathrm{t}}$

$\Rightarrow \mu_{\mathrm{t}}$ is an ideal of BF-algebra $X$.

Conversely

Let $\mu_{\mathrm{t}}$ is an ideal, to prove $\mu$ is fuzzy ideal. Let $\mathrm{x}, \mathrm{y} \in \mathrm{X}$ such that $\mu\left(\mathrm{x}^{*} \mathrm{y}\right)=\mathrm{t}$ and $\mu(\mathrm{y})=\mathrm{s}$ where $\mathrm{t} \leq \mathrm{s}$

Then $\mathrm{x}^{*} \mathrm{y}, \mathrm{y} \in \mu_{\mathrm{t}}$ and hencex $\in \mu_{\mathrm{t},}$ [ since $\mu_{\mathrm{t}}$ is ideal ]

whichimplies $\mu(x) \geq t=\min \{t, s\}=\min \left\{\mu\left(x^{*} y\right), \mu(y)\right\}$. Therefore $\mu$ is a fuzzy ideal of $X$ 
Proposition 3.7.Let $\mu$ be a Doubt fuzzy (DF)ideal of a BF-algebra X. Then the following hold.

(a) If $x \leq y$ then $\mu(x) \leq \mu(y)$, i.e. $\mu$ preserves order.

(b) If $\mu\left(x^{*} y\right)=0$ then $\mu(x) \leq \mu(y)$

(c) If $\mathrm{x} * \mathrm{y} \leq \mathrm{z}$ then $\mu(\mathrm{x}) \leq \max \{\mu(\mathrm{y}), \mu(\mathrm{z})\}$, for all $\mathrm{x}, \mathrm{y}, \mathrm{z} \in \mathrm{X}$

Proof.

(a) Let $\mathrm{x} \leq \mathrm{y}$, then $\mathrm{x} * \mathrm{y}=0$

Now, $\mu(x) \leq \max \left\{\mu\left(x^{*} y\right), \mu(y)\right\}[$ Since $\mu$ is DF ideal ]

$=\max \{\mu(0), \mu(\mathrm{y})\}=\mu(\mathrm{y})[$ since $\mu(0) \leq \mu(\mathrm{y})$ for DF ideal $]$

i.e. $\mu(\mathrm{x}) \leq \mu(\mathrm{y})$ i.e. $\mu$ preserves order.

(b)If $\mu(x * y)=0$,then we have

$\mu(x) \leq \max \{\mu(x * y), \mu(y)\}[$ Since $\mu$ is DF ideal ]

$=\max \{\mu(0), \mu(y)\}=\mu(y),[$ Since $\mu(0) \leq \mu(y)$ for DF ideal $]$

i.e. $\mu(x) \leq \mu(y)$.

(c) Here,

$\mathrm{x} * \mathrm{y} \leq \mathrm{z}$, therefore $(\mathrm{x} * \mathrm{y}) * \mathrm{z}=0$

Now $\mu(\mathrm{x}) \leq \max \left\{\mu\left(\mathrm{x}^{*} \mathrm{y}\right), \mu(\mathrm{y})\right\}(2)$

In particular,

$\mu(\mathrm{x} * \mathrm{y}) \leq \max \{\mu((\mathrm{x} * \mathrm{y}) * \mathrm{z}), \mu(\mathrm{z})\}$

$=\max \{\mu(0), \mu(\mathrm{z})\}=\mu(\mathrm{z})[$ Since $\mu(0) \leq \mu(\mathrm{z})$ for DF ideal $]$

$\therefore \mu(\mathrm{x} * \mathrm{y}) \leq \mu(\mathrm{z})$

$\therefore \max \{\mu(\mathrm{x} * \mathrm{y}), \mu(\mathrm{y})\} \leq \max \{\mu(\mathrm{z}), \mu(\mathrm{y})\}$

(2) and (3) $\Rightarrow \mu(x) \leq \max \{\mu(y), \mu(z)\}$.

Theorem 3.8.If $\mu$ is a Doubt fuzzy (DF)ideal of a BF-algebraX. Then the $\operatorname{set} X_{\mu}=\{x \in X \mid \mu(x)=\mu(0)\}$ is an ideal of $\mathrm{X}$.

Proof. Clearly, $0 \in \mathrm{X}_{\mu}$

Let $\mathrm{x} * \mathrm{y}, \mathrm{y} \in \mathrm{X}_{\mu}$

$\Rightarrow \mu(\mathrm{x} * \mathrm{y})=\mu(\mathrm{y})=\mu(0)$

$\mu(\mathrm{x}) \leq \max \{\mu(\mathrm{x} * \mathrm{y}), \mu(\mathrm{y})\}[$ Since $\mu$ is DF ideal ]

$=\max \{\mu(0), \mu(0)\}=\mu(0)$

$\therefore \quad \mu(\mathrm{x}) \leq \mu(0)$ also $\mu(0) \leq \mu(\mathrm{x})[$ Since $\mu$ is DF ideal ]

$\therefore \quad \mu(\mathrm{x})=\mu(0)$ 
$\therefore \quad \mathrm{x} \in \mathrm{X}_{\mu}$

$\therefore \quad \mathrm{x} * \mathrm{y}, \mathrm{y} \in \mathrm{X}_{\mu} \Rightarrow \mathrm{x} \in \mathrm{X}_{\mu}$

$\Rightarrow \mathrm{X}_{\mu}$ is an ideal.

Theorem 3.9.A fuzzy subset $\mu$ of BF-algebra $X$ is a fuzzy idealof Xiff its complement $\mu^{c}$ is DF ideal of $X$.

Proof.Let $\mu$ be a fuzzy ideal of $\mathrm{X}$, To prove $\mu^{\mathrm{c}}$ is DF ideal. Let $\mathrm{x}, \mathrm{y} \in \mathrm{X}$.

(i) $\mu^{\mathrm{c}}(0)=1-\mu(0) \leq 1-\mu(\mathrm{x})=\mu^{\mathrm{c}}(\mathrm{x})$

i.e. $\mu^{\mathrm{c}}(0) \leq \mu^{\mathrm{c}}(\mathrm{x})[$ since $\mu(0) \geq \mu(\mathrm{x}) \forall \mathrm{x} \in \mathrm{X}]$

(ii) $\quad \mu^{\mathrm{c}}(\mathrm{x})=1-\mu(\mathrm{x}) \leq 1-\min \left\{\mu\left(\mathrm{x}^{*} \mathrm{y}\right), \mu(\mathrm{y})\right\}$

$[\sin c e \mu(x) \geq \min \{\mu(x * y), \mu(y)\}]$

$=1-\min \left\{1-\mu^{\mathrm{c}}(\mathrm{x} * \mathrm{y}), 1-\mu^{\mathrm{c}}(\mathrm{y})\right\}$

$=\max \left\{\mu^{\mathrm{c}}(\mathrm{x} * \mathrm{y}), \mu^{\mathrm{c}}(\mathrm{y})\right\}$

$\Rightarrow \mu^{\mathrm{c}}$ is DF ideal.

Conversely,

Let $\mu^{c}$ is DF ideal of $X$. To prove $\mu$ is fuzzy ideal of $X$

(i) $\quad \mu^{\mathrm{c}}(0) \leq \mu^{\mathrm{c}}(\mathrm{x})$

(ii) $\quad \mu^{\mathrm{c}}(\mathrm{x}) \leq \max \left\{\mu^{\mathrm{c}}\left(\mathrm{x}^{*} \mathrm{y}\right), \mu^{\mathrm{c}}(\mathrm{y})\right\}$

Now (i) $\Rightarrow 1-\mu(0) \leq 1-\mu(x)$

$\Rightarrow \mu(0) \geq \mu(\mathrm{x})$

(ii) $\Rightarrow 1-\mu(\mathrm{x}) \leq \max \left\{1-\mu\left(\mathrm{x}^{*} \mathrm{y}\right), 1-\mu(\mathrm{y})\right\}$

$\Rightarrow \quad 1-\mu(x) \leq 1-\min \{\mu(x * y), \mu(y)\}$

$\Rightarrow \quad-\mu(x) \leq-\min \{\mu(x * y), \mu(y)\}$

$\Rightarrow \quad \mu(x) \geq \min \{\mu(x * y), \mu(y)\}$

$\Rightarrow \quad \mu$ is fuzzy ideal.

Theorem 3.10.Let $\mu$ be a fuzzy subset of a BF-algebra X.If $\mu$ is a DF ideal of X,then the lower level cut $\mu^{t}$ is an ideal of $X$ for all $t \in\left[\begin{array}{ll}0 & 1\end{array}\right], t>\mu(0)$.

Proof.

Let $\mu$ be a DF ideal of $X$. Therefore we have

(i) $\mu(0) \leq \mu(x)$

(ii) $\mu(\mathrm{x}) \leq \max \{\mu(\mathrm{x} * \mathrm{y}), \mu(\mathrm{y})\}$

To prove $\mu^{t}$ is an ideal of $X$. We know that $\mu^{t}=\{x \in X \mid \mu(x) \leq t\}$

Let $x, y \in \mu^{t}$

since $\mu(0) \leq \mu(x) \leq t \Rightarrow 0 \in \mu^{t} \forall t \in\left[\begin{array}{ll}0 & 1\end{array}\right]$

Again let $\mathrm{x}^{*} \mathrm{y}, \mathrm{y} \in \mu^{\mathrm{t}}$

$\therefore \mu(\mathrm{x} * \mathrm{y}) \leq \mathrm{t}, \mu(\mathrm{y}) \leq \mathrm{t}$

Now, $\mu(\mathrm{x}) \leq \max \left\{\mu\left(\mathrm{x}^{*} \mathrm{y}\right), \mu(\mathrm{y})\right\}$

$\leq \max \{\mathrm{t}, \mathrm{t}\}=\mathrm{t}$

hence, $\mu(x) \leq t \Rightarrow x \in \mu^{t}$

$\mathrm{x}^{*} \mathrm{y}, \mathrm{y} \in \mu^{\mathrm{t}} \Rightarrow \mathrm{x} \in \mu^{\mathrm{t}}$

$\therefore \mu^{\text {t }}$ is an ideal. 
Theorem 3.11.Let $\mu$ be a DF ideal of BF-algebra X.Then twolower level cuts $\mu^{t_{1}}, \mu^{t_{2}}$ where $\left(t_{1}<t_{2}\right)$ of $\mu$ are equaliff there is no $x \in X$ such that $t_{1}<\mu(x)<t_{2}$.

Proof.Recall that $\mu^{\mathrm{t}}=\{\mathrm{x} \in \mathrm{X} \mid \mu(\mathrm{x}) \leq \mathrm{t}\}$

Let $\mu^{t_{1}}=\mu^{t_{2}}$ where $\left(\mathrm{t}_{1}<\mathrm{t}_{2}\right)$ and there exists $\mathrm{x} \in \mathrm{X}$ such that $\mathrm{t}_{1}<\mu(\mathrm{x})<\mathrm{t}_{2}$

then $\mu^{t_{1}} \subset \mu^{t_{2}}$, then $\mathrm{x} \in \mu^{t_{2}}$ butx $\notin \mu^{t_{1}}$ which contradicts the fact that $\mu^{t_{1}}=\mu^{t_{2}}$. Hence there is no $\mathrm{x} \in \mathrm{X}$ such that $\mathrm{t}_{1}<$ $\mu(\mathrm{x})<\mathrm{t}_{2}$.

Conversely, suppose that there is no $x \in X$ such that $t_{1}<\mu(x)<t_{2}$. Therefore $\mu^{t_{1}} \subset \mu^{t_{2}}\left(\right.$ since $\left.t_{1}<t_{2}\right)$.Again if $x$ $\in \mu^{t_{2}}$ then $\mu(\mathrm{x}) \leq \mathrm{t}_{2}$ andby hypothesis we get $\mu(\mathrm{x}) \leq \mathrm{t}_{1} \Rightarrow \mu^{t_{2}} \subset \mu^{t_{1}}$. Hence $\mu^{t_{1}}=\mu^{t_{2}}$.

Theorem 3.12.Let $\mu_{1}$ and $\mu_{2}$ be two DF ideal of BF-algebraX. Then $\mu_{1} \cup \mu_{2}$ is also a DF ideal of X.

Proof.Let $\mathrm{x}, \mathrm{y} \in \mathrm{X}$. Now

$\left(\mu_{1} \cup \mu_{2}\right)(0)=\max \left\{\mu_{1}(0), \mu_{2}(0)\right\} \leq \max \left\{\mu_{1}(\mathrm{x}), \mu_{2}(\mathrm{x})\right\}=\left(\mu_{1} \cup \mu_{2}\right)(\mathrm{x})$

$\therefore\left(\mu_{1} \cup \mu_{2}\right)(0) \leq\left(\mu_{1} \cup \mu_{2}\right)(\mathrm{x})$

$\operatorname{Again}\left(\mu_{1} \cup \mu_{2}\right)(x)=\max \left\{\mu_{1}(x), \mu_{2}(x)\right\}$

$\leq \max \left\{\max \left\{\mu_{1}(\mathrm{x} * \mathrm{y}), \mu_{1}(\mathrm{y})\right\}, \max \left\{\mu_{2}(\mathrm{x} * \mathrm{y}), \mu_{2}(\mathrm{y})\right\}\right\}$

$=\max \left\{\max \left\{\mu_{1}(\mathrm{x} * \mathrm{y}), \mu_{2}(\mathrm{x} * \mathrm{y})\right\}, \max \left\{\mu_{1}(\mathrm{y}), \mu_{2}(\mathrm{y})\right\}\right\}$

$=\max \left\{\left(\mu_{1} \cup \mu_{2}\right)(x * y),\left(\mu_{1} \cup \mu_{2}\right)(y)\right\}$

Therefore $\mu_{1} \cup \mu_{2}$ is a DF ideal of $X$.

The above theorem can be generalised as

Theorem 3.13.Let $\left\{\mu_{i} \mid i=1,2,3, \ldots\right\}$ be a family of DF idealof BF-algebra $X$, then $U^{n}{ }_{i=1} \mu_{i}$ is also a DF ideal of $X$. where $U \mu_{\mathrm{i}}=\max \left\{\mu_{\mathrm{i}}(\mathrm{x}): \mathrm{i}=1,2, \ldots\right\}$.

\section{(iii) Product of DF ideals of BF-algebra}

Definition 4.1. Let $\mu_{1}$ and $\mu_{2}$ be two DF idealsof a BF-algebra X. Then their cartesian product is defined by $\left(\mu_{1} \times \mu_{2}\right)(\mathrm{x}, \mathrm{y})=\max \left\{\mu_{1}(\mathrm{x}), \mu_{2}(\mathrm{y})\right\}$ where $\left(\mu_{1} \times \mu_{2}\right): \mathrm{X} \times \mathrm{X} \rightarrow[01] \forall \mathrm{x}, \mathrm{y} \in \mathrm{X}$.

Theorem 4.2 Let $\mathrm{X}$ be a BF-algebra,then the cartesian product $\mathrm{X} \times \mathrm{X} .=\{(\mathrm{x}, \mathrm{y}) \mid \mathrm{x}, \mathrm{y} \in \mathrm{X}\}$ is also a BF-algebra under the binary operation * defined in $\mathrm{X} \times \mathrm{X}$ by $(\mathrm{x}, \mathrm{y})^{*}(\mathrm{p}, \mathrm{q})=(\mathrm{x} * \mathrm{p}, \mathrm{y} * \mathrm{q})$ for all $(\mathrm{x}, \mathrm{y}),(\mathrm{p}, \mathrm{q}) \in \mathrm{X} \times \mathrm{X}$.

Proof. Clearly $(0,0) \in \mathrm{X} \times \mathrm{X}$

(i) $\quad(x, y) *(x, y)=(x * x, y * y)=(0,0)$

(ii) $\quad(\mathrm{x}, \mathrm{y}) *(0,0)=(\mathrm{x} * 0, \mathrm{y} * 0)=(\mathrm{x}, \mathrm{y})$

(iii) $\quad(0,0) *\{(\mathrm{x}, \mathrm{y}) *(\mathrm{p}, \mathrm{q})\}=(0,0) *\left(\mathrm{x} * \mathrm{p}, \mathrm{y}^{*} \mathrm{q}\right)$

$=\{0 *(x * p), 0 *(y * q)\}$

$=\left(p^{*} \mathrm{x}, \mathrm{q}^{*} \mathrm{y}\right)=(\mathrm{p}, \mathrm{q}) *(\mathrm{x}, \mathrm{y})$

Which shows that $(\mathrm{X} \times \mathrm{X},(0,0) *)$ is a BF-algebra.

Theorem 4.3.Let $\mu_{1}$ and $\mu_{2}$ be two DF ideal of BF-algebraX. Then $\mu_{1} \times \mu_{2}$ is also a DF ideal of X $\times X$.

Proof.For any $(x, y) \in X \times X$,

we have $\left(\mu_{1} \times \mu_{2}\right)(0,0)=\max \left\{\mu_{1}(0), \mu_{2}(0)\right\}$

$=\left(\mu_{1} \times \mu_{2}\right)(\mathrm{x}, \mathrm{y})$

$$
\leq \max \left\{\mu_{1}(\mathrm{x}), \mu_{2}(\mathrm{y})\right\}
$$

Therefore $\left(\mu_{1} \times \mu_{2}\right)(0,0) \leq\left(\mu_{1} \times \mu_{2}\right)(x, y)$

Againlet $\left(\mathrm{x}_{1}, \mathrm{x}_{2}\right),\left(\mathrm{y}_{1}, \mathrm{y}_{2}\right) \in \mathrm{X} \times \mathrm{X}$

then $\left(\mu_{1} \times \mu_{2}\right)\left(\mathrm{x}_{1}, \mathrm{x}_{2}\right)=\max \left\{\mu_{1}\left(\mathrm{x}_{1}\right), \mu_{2}\left(\mathrm{x}_{2}\right)\right\}$

$\leq \max \left\{\max \left\{\mu_{1}\left(\mathrm{x}_{1} * \mathrm{y}_{1}\right), \mu_{1}\left(\mathrm{y}_{1}\right)\right\}, \max \left\{\mu_{2}\left(\mathrm{x}_{2} * \mathrm{y}_{2}\right), \mu_{2}\left(\mathrm{y}_{2}\right)\right\}\right\}$

$=\max \left\{\max \left\{\mu_{1}\left(\mathrm{x}_{1} * \mathrm{y}_{1}\right), \mu_{2}\left(\mathrm{x}_{2} * \mathrm{y}_{2}\right)\right\}, \max \left\{\mu_{1}\left(\mathrm{y}_{1}\right), \mu_{2}\left(\mathrm{y}_{2}\right)\right\}\right\}$

$=\max \left\{\left(\mu_{1} \times \mu_{2}\right)\left(\mathrm{x}_{1} * \mathrm{y}_{1}, \mathrm{x}_{2} * \mathrm{y}_{2}\right),\left(\mu_{1} \times \mu_{2}\right)\left(\mathrm{y}_{1}, \mathrm{y}_{2}\right)\right\}$

$=\max \left\{\left(\mu_{1} \times \mu_{2}\right)\left(\left(x_{1}, x_{2}\right) *\left(y_{1}, y_{2}\right)\right),\left(\mu_{1} \times \mu_{2}\right)\left(y_{1}, y_{2}\right)\right\}$

(4) and(5) shows that $\mu_{1} \times \mu_{2}$ is also a DF ideal of $X \times X$.

(iv) Investigation of DF ideals under homomorphism

In this section homomorphism of BF-algebra is defined and some results are studied.

Definition 5.1. Let $X$ and $X^{\prime}$ be two BF-algebras. A mapping $f: X \rightarrow X^{\prime}$ is said to be homomorphismif $\mathrm{f}(\mathrm{x} * \mathrm{y})=\mathrm{f}(\mathrm{x}) * \mathrm{f}(\mathrm{y})$ for all $\mathrm{x}, \mathrm{y} \in \mathrm{X}$.

Theorem 5.2 Let $X$ and $X^{\prime}$ be two BF-algebras and $\mathrm{f}: \mathrm{X} \rightarrow \mathrm{X}^{\prime}$ be a homomorphism Then $\mathrm{f}(0)=0^{\prime}$

Proof. Let $\mathrm{x} \in \mathrm{X}$ therefore $\mathrm{f}(\mathrm{x}) \in \mathrm{X}^{\prime}$

Now $f(0)=f(x * x)=f(x) * f(x)=0 * 0=0$

Theorem 5.3.Letf $: X \rightarrow X^{\prime}$ be an epimorphism of BF-algebras if $v$ be a DF ideal of $X^{\prime}$, then the pre image of 
vunder $\mathrm{f}$ is also a DF ideal of $\mathrm{X}$.

Proof. Recall that $\mathrm{f}^{-1}(v)$ is defined as $\mathrm{f}^{-1}(v)(\mathrm{x})=v(\mathrm{f}(\mathrm{x}))$. Let $\mu$ be the pre image of $v$ under $\mathrm{f}$ then $v(\mathrm{f}(\mathrm{x}))$ $=\mu(\mathrm{x}) \forall \mathrm{x} \in \mathrm{X}$. Since $v$ is DF ideal therefore $v\left(0^{\prime}\right) \leq v(\mathrm{f}(\mathrm{x}))=\mu(\mathrm{x})$. On the other hand $v\left(0^{\prime}\right)=v(\mathrm{f}(0))=\mu(0)$.

$\Rightarrow \mu(0) \leq \mu(\mathrm{x}) \forall \mathrm{x} \in \mathrm{X}$

Again

$\mu(\mathrm{x})=v(\mathrm{f}(\mathrm{x})) \leq \max \left\{v\left(\mathrm{f}(\mathrm{x}) * \mathrm{y}^{\prime}\right), v\left(\mathrm{y}^{\prime}\right)\right\}$ for any $\mathrm{y}^{\prime} \in \mathrm{X}^{\prime}$

Let $\mathrm{y} \in \mathrm{X}$ such that $\mathrm{f}(\mathrm{y})=\mathrm{y}^{\prime}$, then $\mu(\mathrm{x}) \leq \max \left\{v\left(\mathrm{f}(\mathrm{x}) * \mathrm{y}^{\prime}\right), v\left(\mathrm{y}^{\prime}\right)\right\}$

$$
\begin{aligned}
& =\max \{v((\mathrm{f}(\mathrm{x}) * \mathrm{f}(\mathrm{y})), v(\mathrm{f}(\mathrm{y}))\} \\
& =\max \{v(\mathrm{f}(\mathrm{x} * \mathrm{y}), v(\mathrm{f}(\mathrm{y}))\} \\
& =\max \{\mu(\mathrm{x} * \mathrm{y}), \mu(\mathrm{y})\}
\end{aligned}
$$

$\therefore \mu(\mathrm{x}) \leq \max \{\mu(\mathrm{x} * \mathrm{y}), \mu(\mathrm{y})\}$ which is true forallx, $\mathrm{y} \in \mathrm{X}$. Hence $\mu$ is a Doubt fuzzy ideal of $\mathrm{X}$.

Theorem 5.4.Let $\mathrm{f}: \mathrm{X} \rightarrow \mathrm{X}^{\prime}$ be an epimorphism where $\mathrm{X}$ and $\mathrm{X}^{\prime}$ are two BF-algebras if $v$ be a fuzzy subset of $X^{\prime}$,suchthat $f^{-1}(v)$ is DF ideal of $X$,then $v$ is also a DF ideal of $X^{\prime}$.

Proof .Let $\mathrm{u}, \mathrm{v} \in \mathrm{X}^{\prime}$ therefore there exists $\mathrm{x}, \mathrm{y} \in \mathrm{X}$ such that $\mathrm{f}(\mathrm{x})=\mathrm{u}, \mathrm{f}(\mathrm{y})=\mathrm{v}$

Let $\mu$ be the pre image of $v$ under $f$, then $v(f(x))=\mu(x)$ [since $f^{-1}(v)(x)=v(f(x))$ ]

since $\mu$ is DF ideal of $X$

$\therefore \mu(0) \leq \mu(\mathrm{x})$

$\Rightarrow \quad v(\mathrm{f}(0)) \leq v(\mathrm{f}(\mathrm{x}))$

$\Rightarrow \quad v\left(0^{\prime}\right) \leq v(u) \forall u \in X$

Again

$\mu(\mathrm{x}) \leq \max \{\mu(\mathrm{x} * \mathrm{y}), \mu(\mathrm{y})\} \forall \mathrm{x}, \mathrm{y} \in \mathrm{X}$

$\Rightarrow v(\mathrm{f}(\mathrm{x})) \leq \max \{v(\mathrm{f}(\mathrm{x} * \mathrm{y})), v \mathrm{f}(\mathrm{y})\}$

$\Rightarrow v(\mathrm{u}) \leq \max \{v(\mathrm{f}(\mathrm{x}) * \mathrm{f}(\mathrm{y})), v \mathrm{f}(\mathrm{y})\}$

$=\max \{v(\mathrm{u} * \mathrm{v}), v(\mathrm{v})\}$

$v(\mathrm{u}) \leq \max \{v(\mathrm{u} * \mathrm{v}), v(\mathrm{v})\}$ for all $\mathrm{u}, \mathrm{v} \in \mathrm{X}^{\prime}$

Hence $v$ is a DF ideal of $X^{\prime}$.

\section{(v) Conclusion}

In this paper we studiedabout ideals of BF-algebras in context of fuzzy set and we introduced Doubt fuzzy ideals of BF-algebras. We discussed some characterizations of BF- algebras in terms of Doubt fuzzy ideals.In future, the following studies may be carried out (1) Rough fuzzy ideals of BF-algebras (2) $(\in, \in \mathrm{vq})$ Doubt fuzzy ideals of BF-algebras.

\section{(vi) Acknowledgements}

The author would like to thank Dr.D.K.Basnet Associate Professor, Department of Mathematical Sciences,Tezpur University, Tezpur for his constant support and helpful comments.

\section{References}

[1]. Y.Imai and K.Iseki : On Axiom System of Propositional Calculi 15,Proc.Japan Academy,42(1966),19-22.

[2]. J.Neggers and H.S. Kim: on B-algebras, Math.Vensik,54(2002),21-29.

[3]. AndrzejWalendziak: On BF algebras, MathSlovaca,57((2007),No2,119-128.

[4]. A.BorumandSaeid and M.A Rezvani: on Fuzzy BF algebras International Mathematical Forum, 4,No1(2009), 13-25.

[5]. A.BorumandSaeid : Some results in Doubt fuzzy BF- algebras AnaleleUniversitatii Vest Timisoara seriaMathematica Informatica,XLIX,(2011),125-134.

[6]. Young Bae Jun: Doubt fuzzy BCK/BCI algebras, Soochow Journal of Mathematics, Volume 20 No-3,351-358, July 1991.

[7]. R.Biswas: Fuzzy subgroups and antifuzzy subgroups, Fuzzy sets and systems, 35,(1990) 121-124. 